\title{
Hyper/Comics/Con/Text: Institutional Contexts and Interface Design in Online Educational Hypercomics
}

\author{
DAMIAN DUFFY, University of Illinois at Urbana-Champaign
}

\begin{abstract}
When he first coined the term 'hyper-comics' in his 1970 essay 'No More Teacher's Dirty Looks,' Ted Nelson envisioned 'comic strip' images connected via hyperlinks for educational purposes $(2003,316)$. However, while Internet technologies have allowed for various narrative and artistic actualizations of Nelson's futurist prognostications, educational hypercomics remain largely understudied. This paper returns to Nelson's original themes by comparing interface designs and institutional origins of two educational hypercomics: Factoring with $\mathrm{Mr}$. Yang and Mosley the Alien, a comics lecture series on algebraic factoring and The Secret in the Cellar, an annotated webcomic fictionalization of forensic anthropological field work. This analysis will show how sociocultural contexts created by institutional stakeholders give shape to multimodal designs of pedagogical discourse, in order to further knowledge of the evolving practices and processes of integrating comics into e-learning.
\end{abstract}

\section{KEYWORDS}

Hypercomics, educational comics, institutional context, e-learning, multimodality. 


\section{Introduction}

In his essay on personal computers and education, 'No More Teachers Dirty Looks', reprinted in his seminal text Computer Lib/Dream Machines, Ted Nelson critiques 'computer-assisted instruction' trends of the late 1960s and early 1970s for perpetuating longstanding classroom practices that shun students' interests and degrade their active engagement. By placing the onus of informational sequencing, choice, and navigation on the computer rather than the user, students were 'led by the nose through every subject' (2003, 310-11). Nelson instead proposed 'hyper-media', including 'hyper-comics', as forms of 'branching or performing presentations,' that grant students autonomy to explore concepts based on their own choices and interests (2003, 313). It was within the context of this broader critique of educational institutions that Nelson established 'the fundamentals of hypercomics', describing 'a screen-based, digital medium' featuring 'a comic that branches into different pathways based on reader's choice' (Goodbrey 2012, 2).

Since Nelson's early conceptualization of hypercomics, Internet technologies have occasioned multiple examples of comics created to take advantage of the specific affordances of digital distribution and display. Nelson's early focus on reader interaction with branching or otherwise malleable digital objects proved prescient in identifying design issues for hypercomics creators (see, e.g. McCloud 2000; Bigerel 2009; Goodbrey 2013). But although digital interface design issues have been addressed by practitioners and scholars, it has been primarily in terms of aesthetics and narrative construction. The original context of hypercomics design as digital pedagogy has received far less attention.

This lacuna in the study of comics in digital spaces is made all the more problematic by connections drawn by many education scholars between reading comics and learning to be literate in the multiple interconnected modes of meaning making occasioned by the increasing ubiquity of digital media (see, e.g. Schwarz 2006; Jacobs 2007; Duffy 2010). In order to situate my analysis of educational hypercomics at this intersection of aesthetic composition, narrative development, and pedagogical design, I will begin by reviewing research into comics as sponsors of multimodal literacy, and discuss how these findings fit into the broader study of digital and educational comics. Then, I will describe the role of cultural institutions in the general use, design, and distribution of educational and online comics. Drawing upon this research into multimodality and comics in cultural institutions, I will move on to analyzing specific examples of how institutional contexts impact the design of hypercomics made into online learning resources.

\section{Comics, technology, and multimodality}

In the theory of multimodality, the term 'mode' describes '[...] a socially shaped and culturally given semiotic resource for making meaning' (Kress 2010, 79). 'Multimodal phenomena' are created via:

[...] choices from semiotic resources (e.g. language, images, music, mathematical symbolism, gesture and movement) [...] to construct meaning in the context of their instantiation (O'Halloran and Fei 2009, 140).

This emphasis on understanding communication as a network of interrelated multiple modes whose meaning is necessarily contingent upon sociocultural context makes multimodality an 
especially appropriate research framework for comics for two reasons. First, the comics form is characterized by conspicuous multimodality, via its interrelation of visual, textual, and spatial elements; what Stuart Moulthrop describes as the 'interstitial' nature that situates comics in the 'unmapped spaces' between the literary and the cinematic (1999, 200). Second, comics is best defined as a 'social object', whose meaning proceeds from 'an unspecified number of recognition codes' that are 'constantly developing and changing' (Delany 1999, 239). The meaning of comics is contingent upon this shifting combination of style, form, and social context, what Charles Hatfield terms the medium's characteristic 'unfixability' (2005, xiii).

Digital media share these characteristics of interstitial multimodality and sociocultural contingency in several ways. Similarities between comics and digital media's respective deployments of visual and textual modalities comes into sharp relief when we consider the reading practices encouraged by both comics and digital media:

[...] the act of reading a comic cuts much more closely to how our students today receive information. [...] the Internet, where the sites [...] are densely packed and ask readers to move their eyes diagonally and up and down in addition to side to side - the same kind of movements that come with reading comic book panels and pages (Verasci 2008, 97).

Dale Jacobs describes the density of information on a comics page as requiring and teaching 'complex multimodal literacy' $(2007,21)$. The comics form requires a nuanced understanding of hybridized visual and verbal semiotics, of multiple points of view, which in turn complements a pedagogy that teaches students to be self-reflexive and self-critical readers (Schwartz et al. 2006).

Studies of sociocultural effects of comics in the classroom also emphasize how students' connection with comics empowers them as learners in much the same way Nelson suggested hypermedia can allow students to 'relate directly and personally' to subject matter $(2003,310)$. With comics, students develop a 'sense of ownership' often found lacking in traditional classroom curricula (Norton 2003, 145). The comics form encourages '[...] collaboration, community, and communication', predicting ways 'the Internet connects fans along infinite numbers of axes' in digital virtual communities' (Gardner 2012, 104). The combination of image, text, sequence, and composition in the medium makes comics a metaphorical 'source code' for the Internet (Sturm et al. 2014, 8).

The similar affordances of comics and digital media in multimodal literacy education beg the question of how comics remediated within digital spaces behave as pedagogical texts. However, that area of inquiry has remained outside the purview of much of digital comics scholarship. The uses and potentials of educational hypercomics, comics designed for students as online pedagogical texts, are especially underexplored. This is hardly surprising, given that both educational and digital comics have a tendency to fall outside the boundaries that commonly define comics as an institution.

\section{Educational (hyper)comics as institutional outliers}

[...]institutions should not be exclusively identified with organizational entities (for example theatres, galleries, publishing-houses, music labels, etc.), but also with explicit rules (e.g. legal norms, established professions), forms of exchange (markets, social 
prestige) as well as with implicit conventions (behavioral patterns such as social roles) (Hasitschka et al. 2005, 7).

Insofar as comic strips, comic books, and graphic novels are totemic of popular cultural exchange through print mass media and commercial art, 'comics' can be considered a cultural institution. For example, in the United States, in the 1920s and 1930s, the popularity of newspaper comic strips, combined with the concurrent adoption of 'comic-strip-style advertising', blurred the line between entertainment and information consumption, making comics art 'an ingrained feature of American life' (Gordon 1998, 81-82). Within this discourse of 'comics' as a cultural institution, both educational comics and hypercomics are outliers, because both types of comics are largely produced outside the editorial regimes, print production and distribution methods, fan and artist communities, and entertainment industry tie-ins so often associated with comics as popular cultural production.

This is why pioneering creator, publisher, and scholar Leonard Rifas states that educational comics cannot be classified as an industry, subculture, or field, but rather as 'a flexible popular art [...] constantly being reinvented by diverse people working in isolation from each other' $(1991,81)$. The distant relationship between educational comics and the cultural institution of comics means that, despite a long history of comics being used for 'imparting information, shaping attitudes and teaching skills', educational comics are often viewed as 'a perennial novelty item' (Rifas 1988, 145).

As a result of this lack of (sub)cultural recognition, educational comics are 'perhaps the most marginalized and culturally invisible comics category of all' owing to their 'disparate provenance as to purpose and intended audience', their 'limited distribution', and the 'low priority for preservation among their target audience' (Witek 2008, 2-3). Because 'educational comics are didactic, not analytical' (Van Hook 2008, 2), they are markedly 'pragmatic' uses of the comics form; prioritizing communication over aesthetics and information delivery over narrative engagement in order to, '[...] reach the most diverse audiences with the widest range of objectives' (Davidson 2005, 340-341).

Like educational comics, comics on the Internet, sometimes generalized as 'webcomics', are best understood as widespread, diverse, often more connected to various other subcultures, as opposed to a comics-specific subculture akin to the fandom associated with the print comic book industry. There are actually 'many webcomic subcultures, or rather, subcultures in which webcomics are made public (such as gaming or arts and craft)' (Kogel 2013, 9). 'Webcomics cater to a large number of niche audiences[...] interest groups who would otherwise never receive the attention of the mainstream media' (Hicks 2009, 11.15). It should be noted that while 'webcomics' can function as a general term for comics on the Internet, it often connotes digital remediation of print comic strip and comic book serial formats, which can be easily reproduced and sold as print collections. Webcomics are often similar to blogs: websites created and updated by independent, self-employed authors that survive by developing 'a smaller group of dedicated readers' that provide financial support for creative work, 'either through donations or product purchases' with only a small percentage becoming a sustainable way for creators to earn a living (Liming 2012, 20). Print collection sales are a part of this business plan. 'Digital comics' can also function as a generalized term for comics online, but especially connotes 'digital emulations' of print comics formats and buying experiences via in-app purchases of downloaded digital files (Ellis 2011). 
In contrast to these two labels, 'hypercomics' are comics that purposefully eschew print for work that, in the words of artist Neal von Flue, 'blends visual storytelling with any of the unique formal properties of computer technology' (quoted in Goodbrey 2012, 6). I use the term in this sense: 'hypercomics' as comics that incorporate the affordances of digital media to the extent that the comic cannot be reproduced in print without 'portions being resequenced or removed' (Keeper and McDevitt 2012). This rejection of the basic modes of (re)production and distribution at the heart of comics as a popular cultural institution, combined with the preexisting marginality of educational comics, places educational hypercomics at the fringes of comics form and content.

Comics understood as 'an artistic form that historically developed with technologies belonging to print culture' has that history 'both reflected and challenged' in digital spaces (Priego 2012). Because educational hypercomics employ a variety of new media via digital delivery, these works inexorably raise questions as to what qualifies something as a comic as opposed to, for example, animation or illustrated prose. With their respective heterogeneous incorporations of digital interactivity and time-based media (e.g. audio and video), the comics analyzed below compete with and problematize historically prototypical characteristics of their print predecessors, calling into question the extent to which comics theory is applicable in contextualizing and analyzing such online texts. In other words, why call such works comics at all?

\section{Comics and educational institutional memory}

In part, the utility of invoking comics in digital interactive media emerges from comics' mercurial meaning(s): 'Comics' can name a means of communication and/or an aesthetic visual style and/or particular narrative tropes and/or a subculture and/or an industry. Comics exists in 'the liminal space between past and present, text and image, creator and reader[...] a space where these binaries overlap, collaborate, and compete for attention and meaning' (Gardner 2012, 176). Education research into comics has a long history of misconstruing as 'easy' a reading experience defined by complex interwoven 'tensions' (Hatfield 2005, 36). The use of comics in educational institutions activates tensions between institutional goals and reader reactions:

[...] each institution has a narrow agenda and particular reason for using comics in the sponsorship of literacy. [...] the use of multimodal literacy that is being promoted has a particular cast to it, a particular inflection that reflects the agenda of the sponsoring institution. However, the readers who are sponsored may comply with or resist such agendas in ways that are often unpredictable to sponsors (Jacobs 2013, 29-30).

Ironically, part of the potential for comics in inciting creative tensions in educational settings grows out of the medium's historical perception by educators as a negative influence on readers. Stereotypes of comics as necessarily cheap, disposable culture simultaneously sold to and harmful for young readers, arise from the historically dominant conception of comics as commercial product (Groeensteen 2009). But educational comics are often understood as non-commercial, often distributed to target audiences for free or sold to organizations at reduced cost (Jüngst 2011, 96-97). Educational comics have even been used as a form of public relations to counter perceptions of commercial comics as a corruptive influence (Perry et al. 1971, 245). Because they have been historically placed in opposition to popular comics, 
'Many comic book fans are repulsed by any comic with even the faintest odor of the classroom about it[...]' (Rifas 1988, 145).

Because comics is 'a tightly woven matrix of art and commerce', the understanding of comics as a form of expression, appropriate for all types of stories told by all sorts of people, competes with the idea of comics as a narrative genre, 'where the distinctive graphic look and storytelling elements associated specifically with superhero comic books[...] have taken hold in other media like film, television, and video games' (Salkowitz 2012, 16). But, while stereotyping comics as popular culture has been, until very recently, employed to deny the form's cultural legitimacy, those stereotypes have also been used to argue for comics as pedagogically useful. For example, during the 1930s and 1940s National Comics solicited and published reviews and recommendations of prose books from educators and young readers, and in so doing '[...] leveraged the experimental and subversive nature of comics to help[...] create a different kind of community of readers, where comics and classics could co-exist' (Tilley 2012, 12). Popular culture in the classroom is meant to bridge life in and out of school, and ' Teachers can introduce popular culture into their classrooms easily and effectively through comics' (Yang 2003a).

Of course, the conflation of comics with popular culture is as inaccurate as any other sweeping generalization of the amorphous 'social object' of comics. Comparatively few comics works have large audiences, comics are created for readers of a variety of ages, and idiosyncratic stories for small niche audiences are as possible in comics as crowd-pleasing genre fiction. Nonetheless, the association of comics and pop culture escapism persists in educational institutions, including the specific institutional contexts of the educational hypercomics analyzed below.

\section{Factoring with Mr. Yang: Classroom in the comics}

The impact of historical educational institutional meanings on comics is no more explicit than in the example of Factoring with Mr. Yang and Mosley the Alien (Yang 2003b). Factoring [...] was created by award-winning cartoonist and high school computer science teacher Gene Leun Yang as part of a final project for a Masters Degree of Education from California State University at Hayward. Factoring [...] is posted to Yang's website, along with his proposal for the project, Comics in Education (2003a). In the proposal, Yang synthesizes a literature review of education science research on comics-related pedagogy to identify five strengths of comics in education:

1. Motivating: Students have a high affinity for reading and making comics and 'Children[...] have a natural attraction to comics.'

2. Visual: The imagery in comics is able to embody, anthropomorphize, and explain difficult concepts in understandable ways

3. Permanent: Whereas mediums of communication like film, television, and face-to-face lectures are 'fleeting', since the medium controls the passage of time, comics is 'visually permanent', allowing the reader to set their own pace.

4. Intermediate: Yang asserts 'Comics can serve as an intermediate step to difficult disciplines and concepts', a means of teacher scaffolding. Yang cites the common use of comic books to engage reluctant readers. 
5. Popular: Students more readily form personal connections with popular culture and introduction of popular culture in the classroom can help teach 'media literacy' (Yang, 2003a).

As a high school teacher and a graduate student in education, Yang's project proposal, and subsequent project, incorporate implicit educational institutional assumptions about comics. Yang's descriptions of 'motivating', 'intermediate', and 'popular', proceed from perceptions of comics as exclusively for children, and as an 'easy' form of 'debased or simplified word-based literacy' (Jacobs 2007, 21). This is a traditional educationalist view, usually formed at the expense of attention to 'the specificity of the comics reading experience' (Hatfield 2005, 36). In contrast, Yang mitigates the rhetoric of comics as 'easy' with attention to the formal complexities of comics, as in the above description of 'visual permanence' (2003a). Yang explains how attention to such compositional complexities of comics is incorporated into Factoring[...]:

Because comics are visual and static, past, present and future sit on a page next to each other. This gives the reader control over the rate, and even sequence, of information flow. The comic is structured in such a way that students are encouraged to read both backwards and forwards, returning to earlier concepts for review and moving on to more challenging examples once those concepts have been mastered (in Diamond Bookshelf, 2009).

Factoring [...] encourages reading backwards and forwards via a Flash animated interface, one of the most common interfaces for hypercomics generally (Keeper and McDevitt 2012). The hypercomic features two parallel narrative threads in the form of two horizontal rows of comics panels. The top row features Yang's visually minimalist self-caricature lecturing on algebraic factoring. The bottom row features a purple extraterrestrial character named Mosley the Alien, that stands in for the student. Throughout the lesson, Mosley is visible in a panel on the left of the screen, pointing to the left, saying, 'Can we review a bit?' and in a panel on the right of the screen, pointing right and saying, 'Let's keep going!' These panels double as navigational buttons that, along with the keyboard arrow keys, can be clicked to move Mr. Yang's lecture forwards and backwards. In social semiotic terms, Mosley's pointing finger creates a 'unidirectional non-transactional rhetorical vector', gesturing out of the frame, directing reader attention (Kress et al. 1996). Animated panel movements literalize that rhetorical vector, reinforcing linear navigation as a metaphor for learning.

Mr. Yang's lectures vary visually in only small changes in facial expression and the gesture of an arm. Mr. Yang is visible above the waist, in the left of the panel, and occasionally framed in a close up, when transitioning between subtopics in the lecture. In comparison to Yang's art in his graphic novel American Born Chinese, the visual style of Factoring [...] is indicative of the 'pragmatic' nature of educational comics art: single color vector graphics with minimal shading, rendered once, copied, pasted, rescaled and repositioned. Pedagogical complexity appears when, several times during lectures in the top row of panels, a third Mosley panel appears on the bottom row, in the middle of the other two.

In this middle panel, Mosley asks for clarification or more examples, gesturing up to the related panel(s) in the top row. Should the reader share Mosley's need for extra help, (s)he can click on this middle panel, causing the rightmost panel to slide right and out of view, making room for more panels that descend into the top thread. In these panels, Mr. Yang recaps concepts from earlier lessons, or provides additional (often more complex) factoring problems and extended 
discussions of topics, including a hyperlink to a website about prime numbers (Yang 2003b). Thus, far from being ancillary to the comic, these extra panels take advantage of the potential depth of information and 'sense of tactile discovery' that can be incorporated into online comics 'understood as malleable image files on the web' (Kogel 2013, 27, 84).

The animation that inserts or removes panels into and out of the top row implies a continual spatial narrative, with the rest of the comic off screen to the right, an example of Scott McCloud's notion of the screen as a window onto an 'infinite canvas,' instead of a digital remediation of the printed page (McCloud 2000, 222). The animated insertion or removal of panels maintains the linear spatial narrative of the top row, reinforcing the tactile aspect of the comic, the click of the mouse granting users control of composition, while simultaneously recalling the mathematical processes of factoring, where numbers and variables are broken down into component parts. This gives the user a sense of control over the sequence of information flow, in keeping with Ted Nelson's early hopes for educational hypercomics. That sense of interactive control is buttressed by the Mosley character's additional questions, along with Mr. Yang's reactions, which simulate a face-to-face teaching presence often lost or problematized by asynchronous e-learning interfaces (see, e.g. Garrison 2011).

Like its project proposal, Factoring [...] juxtaposes attention to unique formal affordances of the medium with traditional educational institutional approaches to comics in the classroom. In one sense, the hypercomic's performance of classroom instruction uses 'ubiquitous computing devices [...] to do old-fashioned didactic teaching,' which Cope et al. describe as a counterproductive view of contemporary pedagogy $(2010,20)$. The traditional classroom setting is reproduced, with Mr. Yang in front of a dark green background lit by a light green circle, simple shading that reinforces the materiality of the implied chalkboard. 'Implied' because Mr. Yang is never shown writing; instead, equations appear in a sans-serif font, like the typesetting of a textbook projected onto a chalkboard. The effect is interstitial, somewhere between textbook and classroom lecture, between prose and performance. In short, clearly a form of comics, but comics created in a way that is always referential and deferential to traditional formal institutionalized learning.

This design choice builds on the 'intermediate' strength Yang ascribes to comics in education (2003a). The 'About this site' page, describes Factoring[...] as 'designed to be used as supplemental material' assigned as 'a tutorial, an introduction to a unit, or a review before an exam' (Yang 2003b). As information visualization, Factoring[...] largely remediates transmission models of pedagogy; top down information transfer echoed by the two tier layout, with the alien student visually suborned to the teacher, a science-fictional visual metaphor for the student's lack of subject knowledge, in the guise of a friendly referent to comics as popular culture. This is because Factoring [...] is in a sense autobiographical, in that it is a cartoon self-representation of Yang's persona as a teacher, and of his research as a graduate student in teacher education. It is predicated on the author's professional and scholarly experiences with educational institutions.

\section{Animation and HTML architecture in The Secret in the Cellar}

The hypercomic The Secret in the Cellar (Smithsonian National Museum of Natural History, 2009), created as part of the exhibition Written in Bone, is Flash-based with a HTML frame containing backwards and forwards navigational arrows and hypertext links that change with each panel/page. Clicking these hypertext links opens basic HTML pages in a new browser 
window; pop-up window annotations to the comics narrative that provide further context, define technical terms, contain photos of real artifacts referenced in the comic, or present activities that allow 'learners to assess case evidence and test hypotheses-essentially stepping into the role of either an archaeologist or a forensic anthropologist' (Costello et al. 2009, 5). The hypercomic fictionalizes the real life discovery, excavation, and identification of a human skeleton found 'buried in the ruins of a 17th-century house cellar' by an intern in 'The Lost Towns Project, a team of archaeologists digging up colonial Anne Arundel County, Maryland' (Caputo 2009).

The design of Secret in the Cellar elides the characteristics of static images in juxtapositional sequence underpinning Factoring[...]. Instead, with a few exceptions, Secret in the Cellar displays one panel at a time within a dedicated browser window, a 'reductive' version of the 'panel delivery' format, in that it does not take advantage of compositional meanings available through multiple panels juxtaposed in sequence (Goodbrey 2013, 191). In Secret in the Cellar, each panel/page appears in place of the last with transitional animations including cinematic zooms, fade-ins, the movement of objects and/or figures into or out of frame, and the delayed appearance of word balloons over the art, visually literalizing the standard implied reading order of the dialog. Like showing a single panel per 'page,' such inclusion of time-based multimedia (e.g. animation, audio) can interfere with comics' characteristic portrayal of fictive time through static images in compositional space (McCloud 2000, 215-6). This is because time-based media alter the mode of user interaction: '[...] for the comic to still operate as a comic, the rate at which information is absorbed must still be set by the reader' (Goodbrey 2013, 195). Animation competes with rather than compliments the ways comics make meaning because the goal of comics is 'not to make the reader observe motion but rather participate imaginatively in its genesis' (Gunning 2014, 4). McCloud has similarly critiqued the use of navigational hyperlinks separate from narrative content as 'hunt and click' interactions that function as impediments to readers' imaginative immersion $(2006,7)$. Further, the prevalent use of pop-up windows is the Internet definition of interruption, calling attention to the various frames of mediation at play by leaving the comic visible but partially obstructed.

Thus, the salient characteristics of Secret in the Cellar as a hypercomic-limitation of compositional space, combining time-based animation with space-based comics narrative techniques, and requiring readers to navigate multiple ancillary hyperlinks, opening and closing pop-up windows - are all stumbling blocks to readers becoming immersed in the narrative. In most cases this would be seen as inefficient communicative design. But, in Secret in the Cellar, designs that interrupt or complicate narrative progression are ideal because they further the didactic goals of the work's educational institutional context. In their assessment of Secret in the Cellar, Costello et al. note that the hypercomic's design team purposefully avoided 'interesting material[...] extraneous to the learning objectives', suborning storytelling to pedagogy $(2009,4)$. The ultimate goal of this intricate multimedia combination of comics, animation, hyperlinks, and pop-up windows is not to create immersive narrative, but instead to 'move free-choice users to the next level of engagement, from reading to doing[...] from fiction (in this case based on actual events) to nonfiction' (Costello et al. 2009, 5). Narrative engagement is secondary; the educational institutional context uses comics and animation to draw attention, but also to temper narrative engagement by redirecting reader focus on didactic learning through interruptive hyperlinked articles and activities. 


\section{Hypercomics design and contrasting contexts for institutional support}

Like Factoring[...], Secret in the Cellar positions comics as an intermediate step into more complex (in this case, real life scientific) concepts. Secret in the Cellar is also similar to Factoring [...] in terms of target demographics using comics to create 'educational material about archaeological work aimed at a younger audience' (Swogger 2012). Both emerge from educational institutional contexts, but Yang's positions as a cartoonist, teacher, and graduate student all present opportunities for individual expression and achievement. As a result, Factoring [...] presents a more visually unified aesthetic, and a navigational design that focuses primarily on comics as a means of simulating a single form of classroom interaction, remediating the pedagogical model of the teacher-as-expert transmitting information to the student-as-novice.

As an e-learning resource occasioned by a museum exhibition, Secret in the Cellar garners vastly different institutional support and expectations. The comic was created by 'a team of three instructional designers, two subject-matter experts, two illustrators (one for storyline images and one for scientific illustrations in the activities), a Flash developer and a basic HTML developer', a team that included Smithsonian staff, employees from large government subcontractor Booz Allen Hamilton, and individual subcontractors (Costello et al. 2009, 6). The hypercomic's creation was further informed by 'formative evaluations' from focus groups of students grades 7-12, used to edit the comic's script during early design stages (Costello et al. $2009,4)$. Within this institutional context, involving input from a variety of stakeholders, the educational hypercomic takes on a visually diverse, multiplicative design, combining hand drawn, digitally rendered comics illustration with photorealistic scientific illustration with actual photos with quizzes, polls, and text-only articles. Interface design is equally multifarious, as reader control of navigation competes with the animations that punctuate the appearance of each panel/page. Forwards reading is encouraged, each animation functioning as an introduction or reveal of the next page and its attendant hyperlinks, while reading backwards is frustrated, or at least less fluid, requiring users to relinquish control while receiving no new information in return, unless they click on a hyperlink previously unexplored. The museum context creates navigation that is clearly directed, more awkward and measured than the interactive experience of Mr. Yang's single method of explication, complicated only by the potential to increase or decrease the length of Mr. Yang's lectures.

The institutional context of Secret in the Cellar contributes to a more heterogeneous, complicated interactive design, but it also presents an opportunity to complicate educational institutional assumptions about comics pedagogy. During the creation of Secret in the Cellar, the design team 'focused exclusively on a teen audience without much consideration for adult groups' (Costello et al. 2009, 2). However, data from a survey linked to on the last page of the comic found that 'the youngest audiences [...] had lower perceived learning experiences and thought somewhat less of the Webcomic relative to older students and older others' (Costello et al. 2009, 7). While the museum adopted the traditional educationalist assumption that comics primarily appeal to young audiences, the comic's connection to a general audience exhibition implicates a broader range of audience demographics. The more routine data collection regime of the museum, in turn, allowed for findings that call that institutional assumption into question. Thus, varying institutional contexts have the potential to not only impact innovation in hypercomics design, but also to further innovative uses of comics in digital pedagogy overall. 


\section{References}

Bigerel, Y. (2009) 'About digital comics', [online]. Available at http://balak01.deviantart.com/art/about-DIGITAL-COMICS-111966969. Accessed 27 September 2014.

Caputo, J. (2009) 'The Secret in the Cellar - New Exhibit Inspires Webcomic', [online]. Available at http://www.smithsonianmag.com/smithsonian-institution/the-secret-in-the-cellar-newexhibit-inspires-webcomic-38190743/\#WBM7IwqYsf7ypHgL.99. Accessed 12 February 2015.

Cope, B. \& Kalantzis, M. (eds.) (2010) Ubiquitous learning, Champaign, IL: University of Illinois Press.

Costello, R. \& Bliton, D. (2009) 'Assessment of Educational Visual Storytelling at the Smithsonian', in The Interservice/Industry Training, Simulation \& Education Conference, 2009(1), National Training Systems Association.

Davidson, S. (2005) 'The Funnies' Neglected Branch', International Journal of Comic Art, $7(2), 340-357$

Delany, S. (1996) 'The Politics of Paraliterary Criticism', New York Review of Science Fiction, 9(2-4). Rpt. in Shorter Views: Queer Thoughts \& The Politics of the Paraliterary, Hanover: Wesleyan University Press / University Press of New England, 1999, pp. $218-270$

Duffy, D. (2010) 'Out of the margins, into the panels: toward a theory of comics as a medium of critical pedagogy in library education', in M. Accardi, E. Drabinski, and A. Kumbier (eds.), Critical pedagogy and library instruction, Duluth, MN: Library Juice Press.

Ellis, W. (2011) 'The broadcast of comics', [online], 11 October. Available at http://www.warrenellis.com/?p=13421. Accessed 27 September 2014.

Gardner, J. (2012) Projections: Comics and the history of twenty-first-century storytelling, Stanford, CA: Stanford University Press.

Garrison, D. (2011) E-learning in the 21 st century: A framework for research and practice, London: Routledge.

Goodbrey, D. (2011) 'Digital comics: New mutations and innovations' [online]. Available at http://comicsforum.org/2012/02/27/digital-comics-new-mutations-innovations-by-dan iel-merlin-goodbrey. Accessed 27 September 2014.

Goodbrey, D. (2012) 'From comic to hypercomic', Paper presented at the 1st global conference of The graphic novel: An At the Interface project, Mansfield College, Oxford, United Kingdom. Available at http://www.inter-disciplinary.net/at-the-interface/wp-content/uploads/2012/09/danielg oodbrey finalpaper.pdf. Accessed 15 March 2013.

Goodbrey, D. (2013) 'Digital comics-New tools and tropes', Studies in Comics, (4)1, 185-197

Gordon, I. (1993) Comic strips and consumer culture, 1890-1945, Washington, DC: Smithsonian Institution Press.

Gunning, T. (2014) 'The Art of Succession: Reading, Writing, and Watching Comics', Critical Inquiry, 40(3), 36-51

Hasitschka, W., Goldsleger, P. \& Zembylas, T. (2005) 'Cultural institutions studies: Investigating the transformation of cultural goods', The Journal of Arts Management, Law and Society, 35(2), 147-158

Hatfield, C. (2005), Alternative comics: An emerging literature, Jackson, MS: University Press of Mississippi.

Hicks, M. (2009) "“Teh futar": The power of the webcomic and the potential of Web 2.0', in R. Scully and M. Quartly (eds), Drawing the line: Using Cartoons as Historical Evidence, 
Melbourne: Monash University ePress, pp. 11.1-11.20. Available at http://books.publishing.monash.edu/apps/bookworm/view/Drawing+the+Line/77/xht ml/chapter11.html\#ich11en18. Accessed 15 March 2013.

Jacobs, D. (2007) 'More than words: Comics as a means of teaching multiple literacies', English Journal, 96(3), 19-25

Jacobs, D. (2013) Graphic Encounters: Comics and the Sponsorship of Multimodal Literacy, London: Bloomsbury Academic.

Jüngst, H. E. (2010) Information comics, Frankfurt, Germany: Peter Lang.

Keeper, S. and McDevitt, I. (2012) 'Understanding hypercomics', [online]. Available at http://understandinghypercomics.byethost15.com/. Accessed 27 September 2014.

Kogel, D. (2013) 'Rethinking webcomics: webcomics as a screen based medium', (Masters thesis, Art and Culture Studies, University of Jyväskylä). Available at https://jyx.jyu.fi/dspace/handle/123456789/40712. Accessed 27 September 2014.

Kress, G. \& Van Leeuwen, T. (1996) Reading images: The grammar of visual design, London: Routledge.

Kress, G. (2010) Multimodality: A social semiotic approach to contemporary communication, London: Routledge.

Liming, D. (2012) 'Bloggers and Webcomic Artists: Careers in Online Creativity', Occupational Outlook Quarterly, 56(3), 16-21

McCloud, S. (2000) Reinventing comics, New York: HarperCollins.

Moulthrop, S. (1999) 'Misadventure: Future fiction and the new networks', Style, 33(2), 184-203

Norton, B. (2003) 'The motivating power of comic books: Insights from Archie comic readers.', The Reading Teacher, 57(2), 140-7

Neslon, T. (2003) 'Computer Lib/Dream Machines', in N. Montfort, \& N. Wardrip-Fruin (eds.), Digital media Reader. Cambridge, Massachusetts: MIT Press. pp. 301-338.

O'Halloran, K. and Fei, V. (2009) 'Sequential visual discourse frames', in E. Ventola and A.J.M. Guijarro (eds), The World told and the world shown: Multisemiotic issues, New York: Palgrave Macmillan, pp. 139-156

Priego, E. (2012). 'Comics Scholarship in the Digital Age: Towards Media-Specific Research', [online]. Available at http://artspages.wordpress.com/2012/08/24/comics-scholarship-in-the-digital-age-tow ards-media-specific-research/. Accessed 7 November 2013.

Rifas, L. (1988) 'Educational comics: a message in a bubble', Print, 42(6), 145-157.

Rifas, L. (1991) 'AIDS educational comics', Reference Services Review, 19(2), 81 - 87

Salkowitz, R. (2012) Comic-Con and the business of pop culture: What the world's wildest trade show can tell us about the future of entertainment, New York: McGraw-Hill.

Schwartz, A. \& Rubinstein-Ávila, E. (2006) 'Understanding the manga hype: Uncovering the multimodality of comic-book literacies'Journal of Adolescent \& Adult Literacy, 50(1), 40-9

Smithsonian National Museum of Natural History (2009) 'The Secret in the Cellar',[online], 7 February. Available at http://anthropology.si.edu/writteninbone/comic. Accessed 21 February 2015.

Sturm, J. and Bennett, M. (2014) 'The world is made of cheese: The applied cartooning manifesto', [online]. Available at http://issuu.com/cartoonstudies/docs/appliedcartooningmanifesto. Accessed 18 October 2014.

Swogger, J. (2012) 'The sequential art of the past: Archaeology, comics, and the dynamics of an emerging genre', [online]. Available at http://comicsforum.org/2012/06/29/the-sequential-art-of-the-past-archaeology-comics 
-and-the-dynamics-of-an-emerging-genre-by-john-g-swogger/. Accessed 22 October 2014.

Van Hook, J. (2008) 'On the difficulty of characterizing what educational comics are about', ImageTexT: Interdisciplinary Comics Studies, 4(2). Available at http://www.english.ufl.edu/imagetext/archives/v4_2/van_hook/. Accessed 10 November 2013.

Versaci, R. (2001) 'How comic books can change the way our students see literature: one teacher's perspective', The English Journal, 91(2), 61-67

Witek, J. (2008) 'From the margins of the margin: Seeing educational comics', ImageTexT: Interdisciplinary Comics Studies, 4(2), Available at http://www.english.ufl.edu/imagetext/archives/v4_2/witek/. Accessed 10 November 2013.

Yang, G. (2003a) 'Strengths of Comics in Education' [online]. Available at http://www.humblecomics.com/comicsedu/strengths.html. Accessed 10 November 2013.

Yang, G. (2003b) Factoring with Mr. Yang and Mosley the Alien, [online]. Available at http://www.humblecomics.com/factoring/. Accessed 10 November 2013.

Damian Duffy is a cartoonist, writer, curator, lecturer, teacher, Glyph Comics Award-winning graphic novelist, and a $\mathrm{PhD}$ candidate at the University of Illinois in Urbana-Champaign Graduate School of Library and Information Science, where he teaches a course on computers and culture.

Email: dsduffy@illinois.edu 